\title{
PENGARUH KESADARAN WAJIB PAJAK, KUALITAS PELAYANAN FISKUS DAN SANKSI PAJAK TERHADAP KEPATUHAN WAJIB PAJAK ORANG PRIBADI DI KPP PRATAMA BITUNG
}

\author{
Rudolof A. Tulenan ${ }^{1}$, Jullie J. Sondakh ${ }^{2}$, Sherly Pinatik ${ }^{3}$ \\ ${ }^{1,2,3}$ Fakultas Ekonomi dan Bisnis, Jurusan Akuntansi, Universitas Sam Ratulangi, J1. Kampus Bahu, Manado, \\ 95115, Indonesia
}

E-mail : rudolofalexander07@gmail.com

\begin{abstract}
Taxes have been becoming one of many issues dealt in a country. One of the country's incomes comes from taxes, without societies there will be no taxes. Taxes could be defines as a collection done by the government in the purpose of creating a prosperous society, based on the written law about collections, government does not given immediate contraception to the taxers. This research was done in Bitung City, that aim to explain about effect of taxpayer the awareness, the quality of tax authorities services and taxes punishment for the obedience of an individual must pay. This research used quantitative research with 100 samples taken from all taxpayer population at KPP Pratama Bitung. The research's method used in this research is double linear regression, data qualities test, classic assumptions test, hypothesis testing (subject $t$ and subject F). This research's method uses a SPSS software version 23. The hypothesis research's result partially (subject $t$ ) awareness of taxpayer, $t_{\text {count }}$ $=5.045$ and $t_{\text {table }}=1.984$ so $\mathrm{Ha}_{1}$ get accepted then the awareness of taxpayer impacting the must pay obedience. Tax authorities service, $t_{\text {count }}=1.587$ and $t_{\text {table }}=1.984$ so $\mathrm{Ha}_{2}$ denied then the tax authorities service does not impacting the taxpayer obedience. Taxes punishment $t_{\text {count }}=1.554$ and $t_{\text {table }}=1.984$ so $\mathrm{Ha}_{3}$ denied than the tax authorities punishment does not impacting the taxpayer obedience.
\end{abstract}

Keywords : Awareness of taxpayer, Quality of Tax Authorities and Tax Punishment towards the Obedience of Taxpayer Personally.

\section{PENDAHULUAN}

\subsection{Latar Belakang}

Pajak menjadi salah satu masalah yang menjadi perhatian negara. Salah satu sumber pendapatan negara adalah dari pajak, tanpa adanya masyarakat tidak mungkin ada suatu pajak Pajak dapat diartikan sebagai pungutan yang dilakukan negara dengan tujuan untuk mensejaterahkan rakyat, berdasarkan undang-undang yang berlaku di mana atas pungutan tersebut negara tidak memberikan kontraprestasi secara langsung kepada pembayar pajak. Pendapatan negara merupakan sumber utama belanja negara disamping komponen pembiayaan APBN yang meliputi penerimaan pajak dan bukan pajak. Oleh karena itu pajak memiliki peran yang sangat penting dalam penerimaan negara sampai saat ini.

Dalam menjalankan pembangunan suatu negara, pemerintah terus berusaha melakukan setiap perbaikan. Pembangunan nasional adalah kegiatan yang berlangsung terus menerus dan berkesinambungan yang bertujuan untuk meningkatkan kesejahteraan rakyat baik materil maupun spiritual (Waluyo, 2013:2).

Berdasarkan data hingga tahun 2015, wajib pajak (WP) yang terdaftar dalam sistem administrasi Direktorat jendral pajak (DJP) mencapai 30.004.103 WP, yang terdiri atas 2.472.632 WP Badan, 5.239.485 WP Orang Pribadi (OP) Non Karyawan, dan 22.332.086 WPOP Karyawan. Hal ini cukup memprihatinkan mengingat menurut data Badan Pusat Statistik (BPS), hingga tahun 2013, jumlah penduduk Indonesia yang bekerja mencapai 93,72 juta orang. 
Kesadaran wajib pajak adalah suatu kondisi dimana wajib pajak mengetahui, memahami dan melaksanakan ketentuan perpajakan dengan benar dan sukarela. Namun pada kenyataannya masih banyak masyarakat yang belum sadar dengan kewajiban perpajakannya dan tetap berusaha melakukan upaya penghindaran pajak agar tidak menanggung beban pajak yang besar. Kesadaran wajib pajak adalah sebuah itikad baik seseorang untuk memenuhi kewajiban perpajakannya secara tulus ikhlas tanpa adanya imbalan (Susilawati, 2013). Wajib pajak yang sadar akan kewajibannya salah satunya ditunjukkan dengan membayar pajak tepat waktu dan tepat jumlah. Kepatuhan memenuhi kewajiban pajak secara sukarela merupakan tulang punggung dari Self Assessment System.

Selain kesadaran wajib pajak yang menjadi faktor internal dari wajib pajak, faktor eksternal yaitu kualitas pelayanan dari aparat pajak atau fiskus juga sangat mempengaruhi kepatuhan dari wajib pajak itu sendiri ( Santika, 2015). Selama ini banyak ditemukan wajib pajak yang berpersepsi negatif pada aparat pajak yang terlihat pada rendahnya pelayanan pada wajib pajak. Pada kenyataannya masih ada wajib pajak merasa menemui hambatan dalamproses pelayanan yang diberikan oleh aparatur perpajakan yaitu petugas yang lambat, tidak ramah, berbelit-belit, menunggu terlalu lama, kantor dan layanan kurang nyaman, fasilitas yang tidak memadai sehingga menimbulkan keluhan, komplain, dan enggannya mereka menyelesaikan urusan perpajakannya, dan pada gilirannya nanti berakibat pada tumbuhnya sikap tidak patuh dalam melaksanakan kewajiban perpajakan (Hidayatulloh, 2013).

Apabila kualitas pelayanan fiskus sangat baik maka persepsi wajib pajak terhadap pelayanan akan meningkat dan pelayanan fiskus yang baik juga dapat memberikan kenyamanan bagi wajib pajak. Memberikan pelayanan yang baik dapat meningkatkan kepatuhan dari wajib pajak (Rajif, 2012).

Berdasarkan latar belakang tersebut, maka peneliti mengangkat judul "Pengaruh Kesadaran Wajib Pajak, Kualitas Pelayanan Fiskus dan Sanksi Pajak Terhadap Kepatuhan Wajib Pajak Orang Pribadi di KPP Pratama Bitung”.

\section{TINJAUAN PUSTAKA}

\subsection{Pengertian Pajak}

Pengertian pajak menurut pasal 1 ayat 1 undang - undang nomor 28 tahun 2007 tentang perubahan ketiga atas undang - undang nomor 6 tahun 1983 tentang ketentuan umum dan tata cara perpajakan adalah sebagai berikut :

“ Pajak adalah konstribusi wajib kepada Negara yang terutang oleh orang pribadi atau badan yang bersifat memaksa berdasarkan undang - undang, dengan tidak mendapat imbalan secara langsung dan digunakan untuk keperluan negara bagi sebesar-besarnya kemakmuran rakyat. Sedangkan menurut Soemitro, dalam buku Perpajakan Mardiasmo (2016 : 3) pajak adalah iuran rakyat kepada kas Negara berdasarkan undang-undang (yang dapat dipaksakan) dengan tiada mendapat jasa timbal balik (kontraprestasi) yang langsung dapat ditunjukan dan yang digunakan untuk membayar pengeluaran umum.

\subsection{Kesadaran Wajib Pajak}

Kesadaran adalah keadaan untuk mengetahui atau mengerti, sedangkan perpajakan adalah adalah kerelaan memenuhi kewajibananya, termassuk rela memberikan kontribusi dana untuk pelaksanaan fungsi pemerintahan dengan cara membayar kewajiban pajaknya (Yulsiati, 2015:4). Jumlah pendapataan dari sumber pajak tergantung dari kesadaran masyarakat untuk melaksanakan tanggung jawab sebagai wajib pajak, tingkat kesadaran yang tinggi dibutuhkan dalam membantu pendapatan negara. 


\subsection{Pengertian Kualitas Pelayanan Fiskus}

Menurut Boediono (2003) dikutip dalam penelitian Hidayatulloh (2013) mengemukakan pengertian kualitas pelayanan adalah pelayanan kepada pelanggan dikatakan bermutu bila memenuhi atau melebihi harapana pelanggan, atu semakin kecil kesenjangannya antara pemenuhan janji dengan harapan pelanggan adalah semakin mendekati ukuran bermutu.

\subsection{Sanksi Pajak}

Mardiasmo (2016 : 62) menyatakan sanksi perpajakan merupakan jaminan bahwa ketentuan peraturan perundang - undangan perpajakan (norma perpajakan) akan dituruti/ditaati/dipatuhi atau bisa dengan kata lain sanksi perpajakan merupakan alat pencegah (preventif) agar wajib pajak tidak melanggar norma perpajakan. Dalam undang undang perpajakan dikenal 2 macam sanksi, yaitu sanksi administrasi dan sanksi pidana. Sanksi administrasi merupakan pembayaran kerugian kepada negara, khususnya yang berupa bunga dan kenaikan. Sanksi pidana merupakan suatu alat terakhir atau benteng hukum yang digunakan fiskus agar norma perpajakan dipatuhi.

\subsection{Kepatuhan Wajib Pajak}

Kepatuhan wajib pajak dapat didefinisikan sebagai suatu keadaan dimana wajib pajak memenuhi semua kewajiban perpajakan dan melaksanakan hak perpajakannya. Dalam hal ini diartikan bahwa wajib pajak mempunyai kesediaan untuk memenuhi kewajiban perpajakannya sesuai dengan aturan yang berlaku tanpa perlu diadakan pemeriksaan, investasi seksama, peringatan atau ancaman dan penerapan sanksi baik hukum maupun administrasi (Gunandi, 2013 : 94).

\subsection{Hipotesis}

H1 : Kesadaran wajib pajak berpengaruh terhadap kepatuhan wajib pajak.

$\mathrm{H} 2$ : Kualitas pelayanan fiskus berpengaruh terhadap kepatuhan wajib pajak

H3 : Sanksi pajak berpengaruh terhadap kepatuhan wajib pajak

H4 : Kesadaran wajib pajak, kualitas pelayanan fiskus dan sanksi pajak secara bersama berpengaruh terhadap kepatuhan wajib pajak

\subsection{Penelitian Terdahulu}

Penelitian yang dilakukan oleh Fitri wilda 2015 menyatakan bahwa penelitian sebelumnya menggunakan variabel yang sama yaitu pengaruh kesadran wajib pajak, pelayanan fiskus dan sanksi pajak terhadap kepatuhan WPOP Sedangkan Pelayanan Fiskus berpengaruh signifikan Aditya,Rita,Kharis 2016 Penelitian sebelumnya menggunakan variabel yang sama yaitu pengaruh kesadaran wajib pajak.

\section{METODE PENELITIAN}

\subsection{Jenis dan sumber data}

Jenis Penelitian yang digunakan adalah penelitian kuantitatif dengan metode penelitian asosiatif dengan bentuk pola hubungan yaitu hubungan kausal

\subsection{Sampel dan teknik pengambilan sampel}

Berdasarkan data dari KPP Pratama Kota Bitung, wajib pajak yang tercatat adalah sebanyak 42.870. Maka jumlah sampel dalam penelitian dengan margin of error sebesar $10 \%$ adalah :

$$
\mathrm{n}=\frac{42.870}{1+\left(42.870 \times 10 \%{ }^{2}\right)}
$$




$$
\begin{gathered}
\mathrm{n}=\frac{42.870}{1+(42.870 \times 0.01)} \\
\mathrm{n}=\frac{42.870}{1+428,7} \\
\mathrm{n}=\frac{42.870}{429,7} \\
\mathrm{n}=99,76=100
\end{gathered}
$$

\subsection{Metode analisis}

Metode yang digunakan untuk menganalisis data instrumen penelitian berupa kuesioner adalah uji kualitas data dengan melakukan uji validitas dan uji realiabilitas. Selanjutnya agar hasil perhitungan dapat diinterpretasikan dengan akurat dilakukan uji asumsi klasik yang meliputi uji normalitas, uji multikolonieritas, dan uji heterokedastisitas. Terakhir, dilakukan pengujian terhadap model regresi linear berganda yang meliputi uji koefisien determinasi $\left(\mathrm{R}^{2}\right.$ ), uji signifikan simultan (uji F), dan uji t. Semua uji analisis ini dilakukan dengan bantuan software SPSS Statistik versi 23 For Windows.

\section{HASIL ANALISIS DAN PEMBAHASAN \\ 4.1. Hasil analisis \\ Uji Kualitas Data}

Untuk melihat apakah data yang diperoleh dari kuesioner yang dibagikan dapat dipercaya dilakukan uji validitas dan uji reliabilitas. Penelitian ini telah lulus uji validitas dan reliabilitas.

\section{Uji Asumsi Klasik}

Agar hasil penelitian dapat diinterpretasikan dengan akurat maka dilakukan uji asumsi klasik. Penelitian ini telah lulus uji normalitas, multikolonieritas, serta heterokedastisitas.

\section{Uji Hipotesis}

\section{Tabel 1 Koefisien Determinasi $\left(\mathbf{R}^{2}\right)$}

\begin{tabular}{|c|r|r|r|r|r|}
\hline & & & & \multicolumn{5}{c|}{ Model Summary } \\
Model & $\mathrm{R}$ & $\mathrm{R}$ Square & Adjusted R Square & $\begin{array}{c}\text { Std. Error of the } \\
\text { Estimate }\end{array}$ & \multicolumn{1}{c|}{ Durbin-Watson } \\
\hline 1 & $.648^{\mathrm{a}}$ & .419 & .401 & 2.12873 & 1.895 \\
\hline
\end{tabular}

a. Predictors: (Constant), SanksiPajak,KualitasPelayananFiskus, KesadaranWajibPajak

b. b. Dependent Variable: KepatuhanWajibPajak

Sumber: Data Olahan, 2017.

Dari tabel 4.18 dapat dilihat pada Model Summary kolo m R adalah koefisien Pearson (0.648) yang menunjukkan tingkat hubungan antara variabel independen dan variabel dependen. Dan diketahui bahwa R Square adalah 0.419 atau 41,9\%. Angka tersebut mengindikasikan bahwa dalam kepatuhan wajib pajak dipengaruhi oleh kesadaran wajib pajak, kualitas pelayanan fiskus dan sanksi pajak sebesar $41,9 \%$, sedangkan sisanya s ebesar $58,1 \%$ dipengaruhi oleh faktor-faktor lain yang tidak diteliti. 


\section{Hasil Uji t}

Uji t (t-test) ini dimaksudkan untuk mengetahui pengaruh secara parsial (individu) variabel-variabel bebas (kesadaran wajib pajak, kualitas pelayanan fiskus, dan sanksi pajak) terhadap variabel terikat (kepatuhan wajib pajak) atau menguji signifikansi konstanta dan variabel terikat. Hasil perhitungan uji t adalah sebagai berikut.

Tabel 2 Hasil Uji t

\begin{tabular}{|c|c|c|c|c|c|c|}
\hline & \multirow[b]{2}{*}{ Model } & \multicolumn{2}{|c|}{ Unstandardized Coefficients } & $\begin{array}{c}\text { Standardized } \\
\text { Coefficients }\end{array}$ & \multirow[b]{2}{*}{$\mathrm{T}$} & \multirow[b]{2}{*}{ Sig. } \\
\hline & & $\mathrm{B}$ & Std. Error & Beta & & \\
\hline \multirow[t]{4}{*}{1} & (Constant) & 3.273 & 3.003 & & 1.090 & .278 \\
\hline & $\begin{array}{c}\text { KesadaranW } \\
\text { ajibPajak }\end{array}$ & .535 & .106 & .487 & 5.045 & .000 \\
\hline & $\begin{array}{l}\text { KualitasPela } \\
\text { yananFiskus }\end{array}$ & .115 & .073 & .133 & 1.578 & .118 \\
\hline & SanksiPajak & .138 & .089 & .151 & 1.554 & .124 \\
\hline
\end{tabular}

a. Dependent Variable: KepatuhanWajibPajak

Sumber: Data Olahan, 2017

a. Uji t antara kesadaran wajib pajak $\left(\mathrm{X}_{1}\right)$ terhadap kepatuhan wajib pajak $(\mathrm{Y})$

Dari Tabel 4.16 dapat dilihat bahwa untuk variabel kesadaran wajib pajak, $\mathrm{t}_{\text {hitung }}=$ 5.045 dan $t_{\text {tabel }}=1.984$ dan nilai signifikan $0.000<0,05$. Karena $t_{\text {hitung }}>t_{\text {tabel }}$ dan nilai sig. $<$ 0,05 maka dari hasil uji ini dinyatakan $\mathrm{H}_{1}$ ditolak sehingga $\mathrm{Ha}_{1}$ diterima yang artinya kesadaran wajib pajak $\left(\mathrm{X}_{1}\right)$ berpengaruh terhadap kepatuhan wajib pajak.

b. Uji t antara kualitas pelayanan fiskus $\left(\mathrm{X}_{2}\right)$ terhadap kepatuhan wajib pajak (Y)

Dari Tabel 4.16 dapat dilihat bahwa untuk variabel kualitas pelayanan fiskus, $t_{\text {hitung }}=$ 1.578 dan $t_{\text {tabel }}=1.984$ dan nilai signifikan $0.118>0,05$. Karena $t_{\text {hitung }}<t_{\text {tabel }}$ dan nilai sig. $>$ 0,05 maka dari hasil uji ini dinyatakan $\mathrm{HO}_{2}$ diterima sehingga $\mathrm{Ha}_{2}$ ditolak yang artinya kualitas pelayanan fiskus $\left(\mathrm{X}_{2}\right)$ tidak berpengaruh terhadap kepatuhan wajib pajak.

c. Uji t antara sanksi pajak $\left(\mathrm{X}_{3}\right)$ terhadap kepatuhan wajib pajak (Y)

Dari Tabel 4.16 dapat dilihat bahwa untuk variabel sanksi pajak, $\mathrm{t}_{\text {hitung }}=1.554$ dan $\mathrm{t}_{\text {tabel }}=1.984$ dan nilai sinifikan $0.124>0,05$ karena $t_{\text {hitung }}<$ dari $t_{\text {tabel }}$ dan nilai sig. $>0,05$ maka dari hasil uji ini dinyatakan $\mathrm{HO}_{3}$ diterima sehingga $\mathrm{Ha}_{3}$ ditolak yang artinya sanksi pajak $\left(\mathrm{X}_{3}\right)$ tidak berpengaruh terhadap kepatuhan wajib pajak.

\section{Hasil Uji F}

Uji F (kelayakan model) dimaksudkan untuk mengetahui pengaruh variabel-variabel independen (kesadaran wajib pajak, kualitas pelayanan fiskus, dan sanksi pajak) secara simultan (bersama-sama) terhadap variabel dependen (Kepatuhan wajib pajak). Hasil perhitungan uji $\mathrm{F}$ adalah sebagai berikut.

Tabel 3 Hasil Uji F

\begin{tabular}{|r|r|r|r|r|r|}
\hline \multicolumn{1}{|c|}{ Model } & Sum of Squares & df & Mean Square & F & Sig. \\
\hline Regression & 314.336 & 3 & 104.779 & 23.122 & $.000^{\mathrm{b}}$ \\
Residual & 435.024 & 96 & 4.531 & & \\
Total & 749.360 & 99 & & & \\
& & & & & \\
\hline
\end{tabular}

a. Dependent Variable: kepatuhanwajibPajak

b. Predictors: (Constant), SanksiPajak,KualitasPelayananFiskus, KesadaranWajibPajak

Sumber: Data Olahan, 2017. 
Dari tabel 4.17 dapat dilihat bahwa nilai $\mathrm{F}_{\text {hitung }}$ sebesar 23.122 dan $\mathrm{F}_{\text {tabel }}$ sebesar 2.70 dengan nilai signifikan pada tabel menunjukkan angka $0.000<0,05$. Maka dapat disimpulkan bahwa variabel kesadaran wajib pajak, kualitas pelayanan fiskus, dan sanksi pajak berpengaruh secara simultan terhadap kepatuhan wajib pajak.

\subsection{Pembahasan}

\subsubsection{Pengaruh Kesadaran Wajib Pajak terhadap Kepatuhan Wajib Pajak}

Berdasarkan hasil uji t menunjukkan bahwa nilai $t_{\text {hitung }}$ lebih besar dari $t_{\text {tabel }}(5.045>$ 1.984) dan nilai signifikan yang lebih kecil daripada nilai signifikan $5 \%(0.000<0.05)$. Hal ini menunjukkan bahwa kesadaran wajib pajak berpengaruh terhadap kepatuhan wajib pajak orang pribadi. Semakin tinggi kesadaran wajib pajak maka kepatuhan wajib pajak akan tercapai dan menjadi semakin meningkat.. Hal ini selaras dengan penelitian (Safri, 2013), yang menyatakan kesadaran wajib pajak adalah unsur dari dalam diri manusia untuk memahami realitas dan bagaimana mereka bertindak atau bersikap serta kesadaran perpajakan juga seringkali menjadi kendala dalam masalah pengumpulan pajak dari masyarakat. Hasil penelitian ini mendukung hasil penelitian (Mory, 2015) yang menyatakan bahwa kesadaran wajib pajak adalah suatu kondisi dimana wajib pajak mengetahui, dan melaksanakan ketentuan perpajakan dengan benar dan sukarela, oleh karena itu jika wajib pajak semakin memiliki kesadaran dari dalam dirinya maka secara tidak langsung juga akan meningkatkan kepatuhan wajib pajak .

\subsubsection{Pengaruh Kualitas Pelayanan Fiskus terhadap Kepatuhan Wajib Pajak}

Berdasarkan hasil uji $\mathrm{t}$ menunjukkan bahwa nilai $\mathrm{t}_{\text {hitung }}$ lebih kecil dari $\mathrm{t}_{\text {tabel }}(1.554<$ 1.984) dan nilai signifikan yang lebih kecil daripada nilai signifikan 5\% (0.124>0.05). Hal ini menunjukkan bahwa kualitas pelayanan fiskus tidak berpengaruh terhadap kepatuhan wajib pajak orang pribadi. Kualitas pelayanan fiskus merupakan salah satu hal yang meningkatkan minat wajib pajak dalam memenuhi kewajiban perpajakannya dan diharapakan petugas pajak harus memiliki pelayanan yang baik terkait segala hal yang berhubungan dengan pajak. Hal ini selaras dengan penelitian (Pranadata, 2014), semakin buruk pelayanan yang diberikan petugas pajak kepada wajib pajak maka tingkat kepatuhan wajib pajak akan semakin rendah. Kualitas pelayanan pajak merupakan salah satu hal yang meningkatkan minat wajib pajak dalam memenuhi kewajiban perpajakannya dan diharapkan petugas pelayanan pajak harus memiliki kompetensi yang baik terkait segala hal yang berhubungan dengan perpajakan di Indonesia.

Pelayanan pajak yang baik dari instansi pajak merupakan hal yang penting untuk menarik perhatian wajib pajak, wajib pajak berhak mendapatkan pelayanan yang baik tentunya dan dapat membuat tingkat kepatuhan wajib pajak meningkat. Hasil penelitian ini mendukung hasil penelitian (Dewi, 2015) yang menyatakan bahwa Kualitas pelayanan tidak berpengaruh terhadap kepatuhan wajib pajak orang pribadi. Semakin tinggi pelayanan yang diberikan maka akan menimbulkan dampak positif yaitu kerelaan dari wajib pajak dalam melaksanakan kewajibannya membayar pajak.

\subsubsection{Pengaruh Sanksi Pajak terhadap Kepatuhan Wajib Pajak}

Berdasarkan hasil uji $\mathrm{t}$ menunjukkan bahwa nilai $\mathrm{t}_{\text {hitung }}$ lebih kecil dari $\mathrm{t}_{\text {tabel }}(1.554<$ 1.984) dan nilai signifikan yang lebih kecil daripada nilai signifikan 5\% (0.124>0.05). Hal ini menunjukkan bahwa sanksi pajak tidak berpengaruh terhadap kepatuhan wajib pajak orang pribadi. Hal ini selaras dengan penelitian (Asbar, 2014) yang menyatakan bahwa sanksi pajak yang ditetapkan tidak meningkatkan kepatuhan wajib pajak dalam membayar pajak. Kepatuhan wajib pajak semakin berkurang karena masih banyak wajib pajak yang belum sadar dan peduli untuk membayar pajak dan juga dikarenakan sanksi pajak yang dikenakan 
kepada wajib pajak masih rendah sehingga wajib pajak tidak terlalu patuh dengan kewajibannya untuk membayar pajak. Hasil penelitian ini mendukung hasil penelitian (Hananto, 2015) yang menyatakan bahwa sanksi pajak tidak berpengaruh terhadap kepatuhan wajib pajak dalam membayar pajak, hal ini disebabkan karena adanya presepsi wajib pajak mengenai sanksi administrasi dan pidana yang masih ringan oleh sebab itu perlu ada tindak lanjut dari pemerintah.

\subsubsection{Pengaruh Kesadaran Wajib Pajak, Kualitas Pelayanan Fiskus dan Sanksi Pajak Terhadap Kepatuhan Wajib Pajak}

Hasil pengujian menunjukkan bahwa pengaruh variabel bebas kesadaran wajib pajak, kualitas pelayanan fiskus dan sanksi pajak terhadap variabel terikatnya yaitu kepatuhan wajib pajak dilakukan dengan uji $\mathrm{F}$. Hasil perhitugan statistik menunjukkan nilai $F_{\text {hitung }}>\mathrm{F}_{\text {tabel }}$ sebesar $23.122>2.70$ dengan signifikan sebesar $0.000<0,05$. Karena nilai $F_{\text {hitung }}$ lebih besar daripada $F_{\text {tabel }}$ dan signifikan dibawah 0,05 menunjukkan bahwa secara bersama-sama kesadaran wajib pajak $\left(\mathrm{X}_{1}\right)$, kualitas pelayanan fiskus $\left(\mathrm{X}_{2}\right)$, dan sanksi pajak $\left(\mathrm{X}_{3}\right)$ berpengaruh terhadap kepatuhan wajib pajak. hasil penelitian ini sesuai dengan penelitian sebelumnya yang dilakukan oleh restu Mutmainah Marjan (2014) dari variabel kesadaran wajib pajak, kualitas pelayanan fiskus dan sanksi pajak berpengaruh secara simultan terhadap kepatuhan wajib pajak dengan nilai signifikan 0.000 yang artinya lebih kecil dari $0,05(5 \%)$ sehingga dinyatakan berpengaruh secara bersama-sama.

\section{KESIMPULAN DAN SARAN}

\subsection{Kesimpulan}

Berdasarkan hasil penelitian yang telah diuraikan sebelumnya, maka dapat ditarik kesimpulan sebagai berikut :

1. Kesadaran wajib pajak berpengaruh terhadap kepatuhan wajib pajak.

2. Kualitas pelayanan fiskus tidak berpengaruh terhadap kepatuhan wajib pajak.

3. Sanksi pajak tidak berpengaruh terhadap kepatuhan wajib pajak.

4. Kesadaran wajib pajak, kualitas pelayanan fiskus dan sanksi pajak berpengaruh terhadap kepatuhan wajib pajak.

\subsection{Saran}

1. Kantor Pelayanan Pajak Pratama Bitung agar sebaiknya lebih meningkatkan kesadaran wajib pajak dengan cara memberikan informasi dan penyuluhan mengenai fungsi pajak, undang-undang dan ketentuan perpajakan yang berlaku, menghitung, membayar, melaporkan dan membayar pajak secara benar dan tepat waktu pada wajib pajak orang pribadi yang terdaftar di Kantor Pelayanan Pajak Pratama Bitung sehingga dapat meningkatkan penerimana pajak dan kepatuhan wajib pajak.

2. Diharapkan adanya kualitas pelayanan yang baik dari petugas pajak dengan memberikan rasa nyaman kepada wajib pajak, sehingga wajib pajak tau kapan harus membayar pajak. Selain itu petugas pelayanan pajak juga perlu bersikap lebih ramah, memberikan pelayanan dengan cepat dan akurat serta memiliki kompetensi dan wawasan yang luas sehinga dapat mengatasi permasalahan yang dihadapi oleh wajib pajak dan wajib pajak sendiri terhindar dari sanksi perpajakan.

3. Untuk peneliti selanjutnya diharapkan dapat menambah jumlah variabel baik independen maupun dependen, sehingga dapat memperluas kajian mengenai teori dan kondisi yang terjadi dilapangan. 


\section{DAFTAR PUSTAKA}

Aditya Nugroho,Rita Andini, Kharis Raharjo, 2016. Pengaruh Kesadaran Wajib Pajak dan Pengetahuan Perpajakan Wajib Pajak Terhadap Kepatuhan Wajib Pajak Dalam Menbayar Pajak Penghasilan di KPP Semarang Journal Of Accounting, Volume 2 No.2 Maret 2016.

Agoes, Estralita. 2013. Akuntansi Perpajakan. Salemba Empat. Jakarta. Di akses 9 Februari 2017

Andreas, Enni Savitri. 2015. The Effect Of Tax Socializatio, Tax Knowledge Expediency Of Tax ID Number And Service Quality On Tax Payers Compliance With Tax Payers Awareness As Mediating Variables. Department Of Accounting Faculty Of Economic - Riau University, Indonesia

Asbar, Akromi Khairina. 2014. Pengaruh Tingkat Kepuasan Pelayana, Pemahaman Perpajakan, Keadilan Perpajakan, Sanksi Perpajakan dan Kesadaran Perpajakan Terhadap Tingkat Kepatuhan Wajib Pajak Orang Pribadi Pada KPP Senapelan Pekanbaru. Jurnal. Universitas Riau.

Dewi, Fransisca Novieta Afsari. 2013 . Pengaruh Pengetahuan Pajak, Kualitas Pelayanan dan Sanksi Perpajakan Terhadap Kepatuhan Wajib Pajak Orang Pribadi (Studi Empiris di Kantor Pelayanan Pajak (KPP) Pratama Mataram Barat). Skripsi. Yogyakara: Fakultas Ekonomi Jurusan Akuntansi - Universitas Sanata Dharma.

Emielia Mareta, Siti Ragil Handayani, Achmad Husaini. 2014 . Pengaruh Pelaksanaan Sensus Pajak Nasional, Kualitas Pelayanan dan Pengetahuan Pajak Terhadap Kepatuhan Wajib Pajak (Studi pada Wajib Pajak Orang Pribadi di KPP Pratama Batu). Fakultas Ilmu Administrasi Program Studi Perpajakan - Universitas Brawijaya

Etta Mamang Sangadji \& Sopiah. 2013. Perilaku Konsumen. Yogyakarta, Andi.

Fitri Wilda 2015. Pengaruh Kesadaran wajib pajak, pelayanan Fiskus dan Sanksi Pajak Terhadap Kepatuhan WPOP Yang Melakukan Kegiatan Usaha dan Pekerjaan Bebas di Kota Padang.

Ghozali, Imam. 2013. Aplikasi Analisis Multivariat dengan Program IBM SPSS 21.Edisi 7 , Penerbit Universitas Di Ponegoro, Semarang.

Gunandi, 2013. Panduan Komprehnsif Pajak Penghasilan. PT. Niaga Swadaya. Jakarta

Halim, Abdul, Supomo, Bambang, Kusufi, Muhammad. (2013). Akuntansi Manajemen (Akuntansi Manajerial). Edisi Kedua. BPFE, Yogyakarta.

Hananto, Samudra Dhony. 2015. Pengaruh SPPT, Sanksi, Pendapatan Wajib Pajak Terhadap Kepatuhan Wajib Pajak Bumi dan Bangunan. Skripsi, Universitas Dian Nuswantoro Semarang.

Herry (2013). Akuntansi Dasar 1 dan 2 . Cetakan pertama. Grasindo, Jakarta.

Hidayatulloh, Hilman Akbar. 2013 . Pengaruh Kualitas Pelayanan Pajak dan Pengetahuan

Pajak Terhadap Kepatuhan Wajib Pajak (Survey Pada KPP Pratama Bandung Cicadas). Skripsi. Bandung: Jurusan Akuntansi - Universitas Komputer Indonesia.

Ida Bagus Meindra \& I Ketut Jati. 2016.Pengaruh Kesadaran, Kualitas Pelayanan, Pemeriksaan Dan Sanksi Perpajakan Pada Kepatuhan Wajib Pajak Restoran ISSN: 23028556 E-Jurnal Akuntansi Universitas Udayana Vol.16.1. juli (2016): 471-500 